\title{
Crescimento do jundiá (Rhamdia quelen) criado em tanques-rede com diferentes níveis de proteína e energia na dieta
}

\author{
Growth of jundiá (Rhamdia quelen) created in net tanks with different levels of protein and energy
}

in the diet

Crecimiento de jundiá (Rhamdia quelen) creado en tanques de red con diferentes niveles de proteína y energía en la dieta

Adilson Reidel

ORCID: https://orcid.org/0000-0002-1450-9268 Instituto Federal do Paraná, Brasil E-mail: adilson.reidel@ifpr.edu.br

Arcangelo Augusto Signor

ORCID: https://orcid.org/0000-0003-4686-3488 Instituto Federal do Paraná, Brasil E-mail: arcangelo.signor@ifpr.edu.br

Aldi Feiden

ORCID: https://orcid.org/0000-0002-6823-9291 Universidade Estadual do Oeste do Paraná, Brasil E-mail: aldifeiden@gmail.com

Wilson Rogerio Boscolo

ORCID: https://orcid.org/0000-0002-1808-0518 Universidade Estadual do Oeste do Paraná, Brasil E-mail: wilsonboscolo@hotmail.com

Elizabeth Romagoza

ORCID: https://orcid.org/0000-0001-5363-4128 Instituto de Pesca, Brasil

E-mail: e.romagosa@uol.com.br

\begin{abstract}
Resumo
O objetivo do presente trabalho foi avaliar o crescimento de juvenis de jundiá, Rhamdia quelen, criados em tanquesrede, alimentados com rações com diferentes níveis de proteína e energia, durante 324 dias. Foram utilizados 6.300

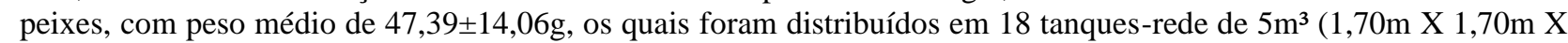
$2,00 \mathrm{~m}$ ), com densidade de 70 peixes $/ \mathrm{m}^{3}$ (350 peixes/tanques-rede). O delineamento experimental foi em esquema fatorial (3×2x3) sendo: três níveis de proteína bruta $(25,30$ e 35\%), dois níveis de energia digestível (3250 e 3500 kcal) e três repetições. O arraçoamento foi realizado duas vezes ao dia ( 9 e $17 \mathrm{~h}$ ) sendo ofertada $50 \%$ da ração calculada (10\% do peso dos animais) em cada alimentação. Observou-se influência positiva dos níveis proteicos da dieta sobre o peso final dos juvenis de jundia até o nível de $30 \%$ de proteína bruta. Com relação a conversão alimentar aparente, observou-se melhores resultados quando alimentados com dietas acima de $30 \%$ de proteína bruta. O jundiá, R. quelen, apresenta melhor desempenho produtivo com ração contendo $30 \%$ de $\mathrm{PB}$, independentemente das concentrações de ED, contudo, recomenda-se o uso de $3.250 \mathrm{kcal} \mathrm{de} \mathrm{ED/kg.}$
\end{abstract}

Palavras-chave: Espécies nativas; Exigência nutricional; Nutrição; Piscicultura intensiva.

\begin{abstract}
The objective of the present work was to evaluate the growth of juveniles of jundia, Rhamdia quelen, raised in net tanks, fed with diets with different levels of protein and energy, for 324 days. 6,300 fish were used, with an average

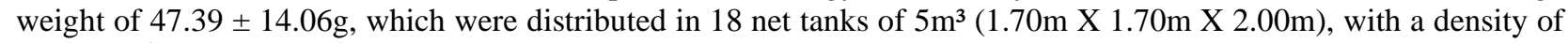
$70 \mathrm{fish} / \mathrm{m}^{3}$ (350 fish/net-tanks). The experimental design was in a factorial scheme $(3 \times 2 \times 3)$ being: three levels of crude protein $(25,30$ and 35\%), two levels of digestible energy (3250 and $3500 \mathrm{kcal})$ and three repetitions. Feeding was carried out twice a day $(9$ am and $5 \mathrm{pm})$ with $50 \%$ of the calculated ration (10\% of the animals' weight) being offered in each feeding. A positive influence of the protein levels of the diet was observed on the final weight of the juveniles of jundia up to the level of $30 \%$ of crude protein. Regarding apparent feed conversion, better results were observed when fed diets above $30 \%$ crude protein. The jundia, R. quelen, presents better productive performance with diets containing $30 \% \mathrm{CP}$, regardless of DE concentrations, however, the use of $3.250 \mathrm{kcal}$ of ED/kg is recommended.
\end{abstract} Keywords: Native species; Nutritional requirement; Nutrition; Intensive fish farming. 


\section{Resumen}

El objetivo del presente trabajo fue evaluar el crecimiento de juveniles de jundia, Rhamdia quelen, criados en tanques de red, alimentados con dietas con diferentes niveles de proteína y energía, durante 324 días. Se utilizaron 6.300 peces, con un peso promedio de $47.39 \pm 14.06 \mathrm{~g}$, los cuales se distribuyeron en 18 tanques netos de $5 \mathrm{~m}^{3}(1.70 \mathrm{~m} \mathrm{X}$ $1.70 \mathrm{~m} X 2.00 \mathrm{~m}$ ), con una densidad de 70 peces $/ \mathrm{m}^{3}$ (350 peces/tanques de red). El diseño experimental fue en un esquema factorial $(3 \times 2 \times 3)$ siendo: tres niveles de proteína cruda $(25,30$ y $35 \%)$, dos niveles de energía digestible (3250 y $3500 \mathrm{kcal}$ ) y tres repeticiones. La alimentación se realizó dos veces al día ( 9 am y 5 pm) ofreciéndose en cada alimentación el 50\% de la ración calculada (10\% del peso de los animales). Se observó una influencia positiva de los niveles de proteína de la dieta sobre el peso final de los juveniles de jundia hasta el nivel del $30 \%$ de proteína cruda. Con respecto a la conversión aparente del alimento, se observaron mejores resultados cuando se alimentaron con dietas superiores al 30\% de proteína cruda. El jundiá, $R$. quelen, presenta mejor desempeño productivo con dietas que contienen $30 \%$ de PB, independientemente de las concentraciones de DE, sin embargo, se recomienda el uso de 3.250 $\mathrm{kcal}$ de DE/kg.

Palabras clave: Especies nativas; Requerimiento nutricional; Nutrición; Piscicultura intensiva.

\section{Introdução}

O Brasil possui inúmeras espécies de peixes nativos com potencial para o cultivo, sendo que um dos bagres que vem despontando é o jundiá, Rhamdia quelen. É a espécie que apresenta bons resultados em função de ser dócil, com hábito alimentar onívoro, desenvolvimento rápido, rústica e resistência ao manejo, crescimento acelerado, boa eficiência alimentar e, sobretudo por apresentar carne saborosa, sem espinhos intramusculares além de, apresentar boa aceitação pelo mercado consumidor (Baldisserotto \& Randuz Neto, 2005). Apresenta crescimento rápido, inclusive nos meses mais frios do ano, sendo que a faixa de conforto térmico varia entre 18 e $28^{\circ} \mathrm{C}$, tolerando baixos níveis de oxigênio na água (Carneiro et al., 2002; Fracalossi et al., 2002), sendo que Piedras et al. (2004) recomenda para a espécie a temperatura média de $23,7^{\circ} \mathrm{C}$, por apresentar melhor crescimento.

A criação de jundiá $R$. quelen, em tanques-rede é alternativa de produção em locais onde a instalação de sistemas convencionais de produção não é possível ou adequados (Carneiro, 2004) em função das dificuldades de manejos a serem empregadas na criação como alimentação, biometrias e despesca regular para comercialização (Signor et al., 2020). A produção de peixes neste sistema é definida por volume delimitado que permite a livre e, constante circulação de água, podendo ser fechados de tela em todos os lados e/ou na parte superior, de formas circulares, retangulares, poligonais ou quadradas, sendo esta última a mais comum para represas e reservatórios (Carneiro, 2004). Devido suas características de rusticidade e adaptabilidade, o jundia torna-se uma espécie com potencial para este sistema de criação em tanques-rede, principalmente no Sul do Brasil em função de temperatura da água mais amena (Signor et al., 2020).

Rações balanceadas vêm sendo utilizadas de forma decisiva no cultivo de peixes quer como fator de sustentabilidade ecológica ou de viabilidade técnico-econômica da atividade (Lazzari et al., 2006). Deve-se considerar na criação de peixes que as dietas devem conter uma mistura de ingredientes com adequadas quantidades protéicas, energéticas, vitamínicas e minerais. Contudo, a quantidade de cada ingrediente usado depende de vários fatores, incluindo exigências para a espécie, palatabilidade, custo, disponibilidade e processamento adequados (Coldebella \& Radünz Neto, 2002). Contudo devem, ser utilizados alimentos com bom aporte de nutrientes, homogeneidade de composição e disponibilidade constante no mercado (Lovell, 1991).

Um dos itens decisivos para o crescimento do animal é o perfil de aminoácidos apresentado pela proteína utilizada na dieta. Para que não sejam fornecidos níveis excessivos deste nutriente, torna-se de fundamental importância determinar as exigências proteicas dos peixes para cada fase da criação (Furuya et al., 1996), para assim formular rações balanceadas e de menor custo. A utilização das fontes energéticas não protéicas apresenta grande importância, pois as concentrações de proteína e energia devem estar balanceadas para bom desempenho dos peixes, apresentando bons índices de conversão alimentar e retenção de proteína na carcaça (Ellis \& Reigh, 1991). 
Trabalhos de pesquisa vêm sendo desenvolvidos com enfoque especial na relação entre os níveis proteicos e energéticos da dieta (proteína/energia, P/E), isto porque os peixes e outros monogástricos se alimentam até suas necessidades energéticas serem supridas (Lowell, 1998). Sendo que, se estas dietas apresentarem baixa relação P/E podem fazer com que os peixes, ao se saciarem, não tenham suprido suas necessidades protéicas e, assim, não expressarem o máximo potencial de crescimento, podendo ainda acumular gordura na carcaça (Duan et al., 2001, Ng et al., 2001). Todavia, se esta relação for muito alta, ao se saciarem, a proteína será ingerida, não havendo na dieta energia suficiente para metabolizá-la até a formação dos tecidos (Shiau \& Lan, 1996). Segundo os autores, parte dessa proteína em excesso será utilizada como energia e, consequentemente, haverá aumento dos custos dessa dieta, além do que, o nitrogênio de sua composição será excretado degradando o meio (água).

Diante do exposto, o objetivo do presente trabalho foi avaliar o crescimento de juvenis de jundiá, Rhamdia quelen, criados em tanques-rede, alimentados com rações com diferentes níveis de proteína e energia

\section{Metodologia}

O presente trabalho foi desenvolvido no Reservatório da Usina Hidroelétrica ITAIPU Binacional, no município de Santa Helena/Paraná, localizado na área de transição do reservatório, junto ao Refúgio Biológico de Santa Helena, nas

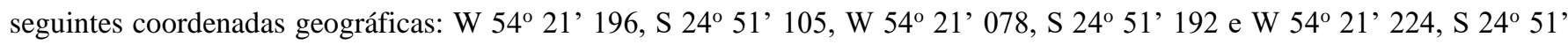
143.

Os tanques-rede (TR) foram instalados em duas linhas paralelas, com nove unidades em cada linha, o espaçamento entre linhas com aproximadamente 20,0m e espaçamento de $2 \mathrm{~m}$ entre tanques-rede (Figura 1). A profundidade do local com aproximadamente $8,0 \mathrm{~m}$.

Figura 1. Distribuição experimental no sistema de tanques-rede.

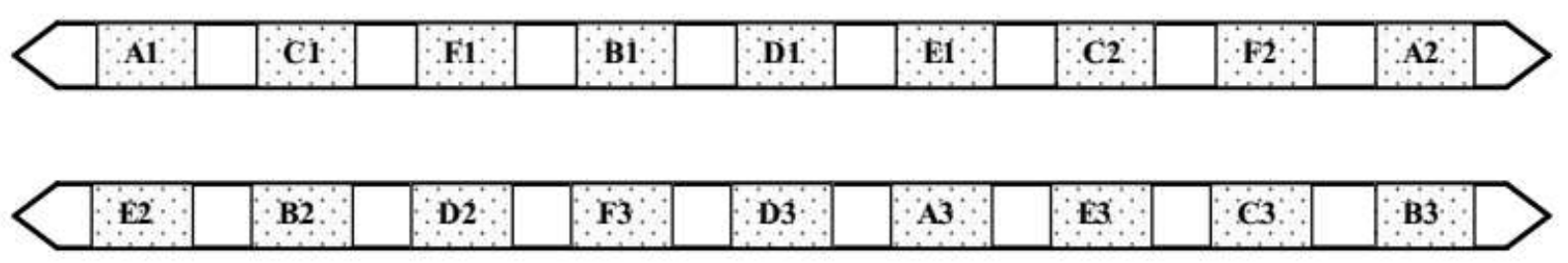

Legenda: A: 25\% de PB e 3250Kcal de ED; B: 30\% de PB e 3250Kcal de ED; C: $35 \%$ de PB e 3250Kcal de ED; D: $25 \%$ de PB e $3500 K c a l$ de ED; E: $30 \%$ de PB e 3500Kcal de ED e F: 25\% de PB e 3500Kcal de ED

Fonte: Autores.

Os 18 tanques-rede utilizados possuíam 5,0 $\mathrm{m}^{3}$ (1,70m X 1,70m X 2,00m - lado x lado x profundidade), sendo que $0,25 \mathrm{~m}$ permaneciam suspensos na superfície da água devido à estrutura de flutuabilidade do tanque. A estrutura rígida dos tanques era de alumínio, a tela de arrame galvanizado revestida de PVC (malha 20,0 mm) e um anel de alimentação de PVC (malha 5,0 mm). Sobre a superfície dos tanques-rede, instalou-se uma tela de sombrite com redução de $75 \%$ da intensidade luminosa.

Foram elaboradas seis dietas experimentais com três níveis de proteína bruta (PB) $(25 ; 30$ e 35\%) e dois níveis de energia digestível (ED) (3250 e $3500 \mathrm{kcal} / \mathrm{Kg}$ ) (Tabela 5), sendo as mesmas isocálcicas e isofosfóricas. 
Tabela 1. Composição percentual e química das rações experimentais com diferentes níveis de proteína e energia (matéria natural).

\begin{tabular}{|c|c|c|c|c|c|c|}
\hline \multirow{4}{*}{ Ingredientes $(\%)$} & \multicolumn{6}{|c|}{ Níveis de energia (kcal/kg) } \\
\hline & \multicolumn{3}{|c|}{3250} & \multicolumn{3}{|c|}{3500} \\
\hline & \multicolumn{6}{|c|}{ Níveis de proteína (\%) } \\
\hline & 25 & 30 & 35 & 25 & 30 & 35 \\
\hline Arroz quirera & 30,000 & 30,000 & 30,000 & 30,000 & 30,000 & 30,000 \\
\hline Farinha de carne e ossos & 4,787 & 4,787 & 4,787 & 4,787 & 4,787 & 4,787 \\
\hline Farinha de peixe & 3,334 & 3,334 & 3,334 & 3,334 & 3,334 & 3,334 \\
\hline Farinha de vísceras de aves & 15,000 & 15,000 & 15,000 & 15,000 & 15,000 & 15,000 \\
\hline Farelo de soja & 14,379 & 27,215 & 40,051 & 15,390 & 28,225 & 41,061 \\
\hline Milho & 30,673 & 18,146 & 5,618 & 25,057 & 12,528 & 0,001 \\
\hline Antioxidante (BHT) & 0,030 & 0,030 & 0,030 & 0,030 & 0,030 & 0,030 \\
\hline Calcário calcítico & 0,027 & 0,107 & 0,188 & 0,000 & 0,081 & 0,161 \\
\hline Fosfato bicálcico & 0,496 & 0,249 & 0,002 & 0,536 & 0,290 & 0,043 \\
\hline Óleo de soja & 0,323 & 0,182 & 0,041 & 4,916 & 4,775 & 4,633 \\
\hline Suplemento min. Vitim. ${ }^{1}$ & 0,400 & 0,400 & 0,400 & 0,400 & 0,400 & 0,400 \\
\hline Propionato de cálcio & 0,050 & 0,050 & 0,050 & 0,050 & 0,050 & 0,050 \\
\hline Sal comum & 0,500 & 0,500 & 0,500 & 0,500 & 0,500 & 0,500 \\
\hline Total & 100,00 & 100,00 & 100,00 & 100,00 & 100,00 & 100,00 \\
\hline \multicolumn{7}{|l|}{ Nutrientes calculados $(\%)^{2}$} \\
\hline Amido & 41,010 & 33,205 & 25,400 & 37,511 & 29,705 & 21,901 \\
\hline Cálcio & 1,450 & 1,450 & 1,450 & 1,450 & 1,450 & 1,450 \\
\hline Proteína bruta & 25,000 & 30,000 & 35,000 & 25,000 & 30,000 & 35,000 \\
\hline Energia digestível $(\mathrm{kcal} / \mathrm{kg})^{3}$ & 3250 & 3250 & 3250 & 3500 & 3500 & 3500 \\
\hline Fibra bruta & 1,923 & 2,442 & 2,961 & 1,875 & 2,394 & 2,913 \\
\hline Fósforo total & 1,000 & 1,000 & 1,000 & 1,000 & 1,000 & 1,000 \\
\hline Gordura & 4,279 & 3,879 & 3,479 & 8,645 & 8,245 & 7,845 \\
\hline Linoléico & 1,242 & 1,019 & 0,796 & 3,623 & 3,399 & 3,176 \\
\hline Lisina & 1,281 & 1,606 & 1,932 & 1,295 & 1,620 & 1,946 \\
\hline Metionina + Cistina & 0,905 & 1,021 & 1,138 & 0,897 & 1,013 & 1,130 \\
\hline Metionina & 0,455 & 0,517 & 0,579 & 0,452 & 0,514 & 0,576 \\
\hline$\overline{\mathrm{ED}: \mathrm{PB} \text { (kcal de ED/g PB) }}$ & 13,0 & 10,8 & 9,3 & 14,0 & 11,7 & 10,0 \\
\hline
\end{tabular}


${ }^{1}$ Suplemento mineral e vitamínico: Met 5\%, Mn 3.750mg, BHT 0,5\%, Ca 43g, Zn 70mg, Fe 15.000mg, Cu 2.000mg, Co 50mg, I 125mg, Se 0,2mg, Vit A 5000UI, Vit D3 300.000UI/kg, Vit E 80mg, Vit K3 2.260mg, Vit B1 2.500mg, Vit B2 5.000mg, Vit B6 2.500mg, Vit B12 $7.500 \mathrm{mg}$, Vit C 75.000mg, Ác Fólico 500mg, Ác. Pantotênico 12.500mg, Niacina 20.000mg, Colina 200.000mg, Lisina 4\%, Biotina $150 \mathrm{mg} / \mathrm{kg}$.

${ }^{2}$ Valores dos \% dos nutrientes propostos por Rostagno et al., (2005).

${ }^{3}$ Valores de energia digestível dos alimentos baseados em Boscolo et al. (2002) e Pezzato et al. (2002).

Fonte: Autores.

Os alimentos (arroz quirera, farinha de carne e ossos, farinha de peixe, farinha de vísceras de aves, farelo de soja e milho) foram pesados e moídos (moinho tipo martelo com peneira de malha 0,8mm). Posteriormente, os ingredientes moídos foram transferidos a um misturador horizontal, sendo adicionados os micronutrientes e conservantes e, finalmente o óleo. As rações foram submetidas ao processo de extrusão (peletes de 4,0 e 6,0mm), para utilização nas fases inicial e final, respectivamente. A seguir, foram secas, embaladas e identificadas. Posteriormente à secagem, as rações foram submetidas ao teste de flutuabilidade, onde se constatou que todas as formulações apresentaram $100 \%$ de flutuabilidade.

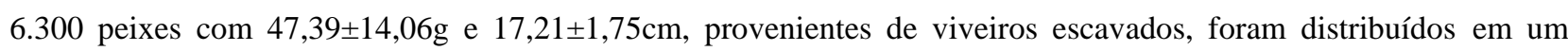
delineamento inteiramente casualizado em 18 tanques-rede com densidade de estocagem de 70 peixes $/ \mathrm{m} 3$, perfazendo 350 peixes em cada tanque-rede. O delineamento foi em esquema fatorial 3 x 2 × 3 - proteína x energia x repetições.

Diariamente, a ração foi pesada e oferecida duas vezes ao dia aos peixes às ( 9 e $17 \mathrm{~h}$ ) sendo $50 \%$ em cada alimentação. Biometrias a cada 28 dias foram realizadas em todos os tanques, com no mínimo $10 \%$ dos animais de cada tanque-rede, sendo capturados e pesados(g).

$\mathrm{O} \mathrm{pH}$, a condutividade elétrica $(\mu \mathrm{S} / \mathrm{cm})$ e o oxigênio dissolvido $(\mathrm{mg} / \mathrm{L})$ da água foram medidos quinzenalmente, enquanto à temperatura $\left({ }^{\circ} \mathrm{C}\right)$ e a transparência $(\mathrm{m})$ da água foi monitorada, diariamente, pela manhã $(9 \mathrm{~h})$ e à tarde $(16 \mathrm{~h} 30 \mathrm{~min})$, dentro dos tanques-rede e no ambiente externo (30 metros).

Ao final do período experimental, todos os peixes foram mantidos em jejum por 12 horas, contados e pesados. Foram calculados os dados de peso final (PF), ganho de peso (GP), ganho de peso diário (GPd), sobrevivência (SO) e conversão alimentar aparente (CAA). Foram tomadas estas medidas por se tratar de métodos quantitativas de avaliação de dados (Pereira et al., 2018).

Os dados estatísticos foram analisados por meio da avaliação dos possíveis efeitos das quantidades de proteína bruta (PB) e energia digestível (ED), nas composições das rações sobre o ganho de peso (GP), sobrevivência (SO) e conversão alimentar aparente (CAA) através das análises de variância (ANOVA- bifatorial para SO e GP; Gotelli e Allison (2004)) e de covariância (ANCOVA-bifatorial para CA; Huitema (1980)) com a SO como covariável. A notação computacional para estes modelos lineares pode ser assim representada:

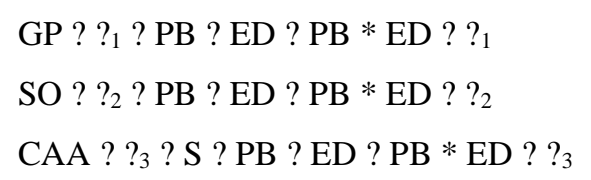

Onde $?_{1}, ?_{2}$ e $?_{3}$ são parâmetros e $?_{1}, ?_{2}$ e $?_{3}$ são resíduos $\left(? \sim N\left(0, ?^{2}\right)\right)$ do modelo.

Após o ajuste do modelo completo, a interação e, posteriormente os fatores não significativos $(p>0,05)$ foram gradativamente removidos de modo a manter no modelo estatístico somente, os termos significativos ( $<<0,05)$. As comparações múltiplas de médias foram realizadas para os fatores significativos utilizando-se o teste Tukey (Zar, 1999).

Os pressupostos dos modelos $\left(? \sim N\left(0, ?^{2}\right)\right)$ foram checados conforme Gotelli \& Allison (2004) e Huitema (1980) sendo que, para todos os testes, as hipóteses de homogeneidade de variância e normalidade nos resíduos não foram rejeitadas 
( $\mathrm{p}>0,05)$. Todas as análises estatísticas foram realizadas com auxílio do protocolo General Linear Models (GLM) do software Statistica $7.1^{\circledR}$.

\section{Resultados e Discussão}

Neste estudo, os valores médios da temperatura da água $\left(23,6^{\circ} \mathrm{C}\right)$ mantiveram-se dentro da faixa ideal para a criação de peixes (Boyd, 1990). A variação entre as médias máximas e mínimas de temperatura da água foi de: $27,8 \pm 2,4^{\circ} \mathrm{C}$ e 20,2 $\pm 1,9^{\circ} \mathrm{C}$, respectivamente. Estes resultados corroboram os de Piedras et al. (2004), que avaliaram o crescimento de juvenis de jundiá, $R$. quelen, em diferentes temperaturas da água $\left(20^{\circ}, 23^{\circ}\right.$ e $\left.26^{\circ} \mathrm{C}\right)$ e, observaram que o melhor crescimento foi registrado com a temperatura média de aproximadamente $23,0^{\circ} \mathrm{C}$. Segundo Carneiro et al. (2002) e Fracalossi et al. (2002), o conforto térmico para a mesma espécie, se encontra entre 18,0 e $28,0^{\circ} \mathrm{C}$, semelhante ao observado neste estudo. Baldisserotto e Randuz Neto (2005) mostraram que o jundiá sobrevive a ampla variação de temperatura da água $\left(3,0\right.$ a $\left.32,0^{\circ} \mathrm{C}\right)$ e destacaram a necessidade de adaptação ao ambiente. Entretanto, a literatura é carente de informações sobre os valores mais precisos de temperatura da água para os melhores resultados de ganho de peso e conversão alimentar para esta espécie quando mantida em tanques-rede.

O potencial hidrogênionico da água oscilou no decorrer do experimento, se estabilizando em torno de 7,44 $\pm 0,14$. Estes resultados confirmam Baldisserotto e Randuz Neto (2005) os quais verificaram que, o melhor crescimento foi obtido em exemplares juvenis de jundiás mantidos em pH entre 4,0 e 9,0. Já a condutividade elétrica da água registrada foi de $55,73 \pm 5,50 \mu \mathrm{S} / \mathrm{cm}$, que se manteve dentro dos padrões aceitáveis para a maioria das espécies de peixes (Boyd, 1990).

Houve variação da transparência da água monitorada fora dos tanques-rede. O valor observado foi de $2,73 \pm 0,74 \mathrm{~m}$, possibilitando a visualização dos peixes no fundo do TR. Provavelmente, a transparência pode ter afetado a performance dos animais, sendo que estes resultados diferem dos obtidos por Carneiro e Mikos (2005) e Felin Junior et al. (2007) onde os mesmos observaram valores máximos de transparência de $0,48 \mathrm{~m}$, pois, esta é uma característica variável e dependente do local de cultivo.

Observou-se influência positiva dos níveis proteicos da dieta sobre o peso final dos juvenis de jundia (Tabela 2), até o nível de $30 \%$ de proteína bruta que apresentou os melhores resultados, não diferindo $(\mathrm{P}>0,05)$ da dieta com $35 \%$. Por outro lado, os níveis energéticos não influenciaram no peso final dos jundiás.

Tabela 2. Valores médios de peso inicial, peso final, ganho em peso médio diário, conversão alimentar aparente e sobrevivência do jundiá ( $R$. quelen) criado em tanques-rede com diferentes níveis de energia digestível e proteína bruta

\begin{tabular}{|c|c|c|c|c|c|c|}
\hline \multirow{4}{*}{ Parâmetros } & \multicolumn{6}{|c|}{ Níveis de energia (kcal/kg) } \\
\hline & \multicolumn{3}{|l|}{3250} & \multicolumn{2}{|l|}{3500} & \\
\hline & \multicolumn{6}{|c|}{ Níveis de proteína (\%) } \\
\hline & 25 & 30 & 35 & 25 & 30 & 35 \\
\hline \multirow{2}{*}{ Peso inicial $(\mathrm{g})$} & $49,1 \pm$ & $49,1 \pm$ & $48,64 \pm$ & $49,9 \pm$ & $48,57 \pm$ & $47,21 \pm$ \\
\hline & $10,2^{\mathrm{AX}}$ & $12,3^{\mathrm{AX}}$ & $11,4^{\mathrm{AX}}$ & $9,8^{\mathrm{AX}}$ & $13,5^{\mathrm{AX}}$ & $13,8^{\mathrm{AX}}$ \\
\hline \multirow{2}{*}{ Peso final $(g)$} & $334,0 \pm$ & $445,9 \pm$ & $479,8 \pm$ & $344,8 \pm$ & $470,1 \pm$ & $482,5 \pm$ \\
\hline & $31,8^{\mathrm{BX}}$ & $37,8^{\mathrm{AX}}$ & $26,7^{\mathrm{AX}}$ & $10,8^{\mathrm{BX}}$ & $21,4^{\mathrm{AX}}$ & $18,7^{\mathrm{AX}}$ \\
\hline Ganho de peso/dia (g) & $0,88^{\mathrm{BX}}$ & $1,22^{\mathrm{AX}}$ & $1,39^{\mathrm{AX}}$ & $0,91^{\mathrm{BX}}$ & $1,30^{\mathrm{AX}}$ & $1,40^{\mathrm{AX}}$ \\
\hline Conversão alimentar aparente & $3,33^{\mathrm{BX}}$ & $2,48^{\mathrm{AX}}$ & $2,31^{\mathrm{AX}}$ & $2,85^{\mathrm{BX}}$ & $2,35^{\mathrm{AX}}$ & $2,12^{\mathrm{AX}}$ \\
\hline Sobrevivência (\%) & $70,71^{\mathrm{AX}}$ & $78,48^{\mathrm{AX}}$ & $80,86^{\mathrm{AX}}$ & $60,86^{\mathrm{AX}}$ & $82,67^{\mathrm{AX}}$ & $73,14^{\mathrm{AX}}$ \\
\hline
\end{tabular}


Onde: X e Y diferem para o fator ED e A e B diferem para o fator PB. Médias na mesma linha seguida de letras distintas diferem ao nível de $5 \%$ de probabilidade.

Fonte: Autores.

Após 324 dias, o ganho em peso aumentou significativamente à medida que a concentração proteica aumentou de 25 para 30 ou 35\%. Entretanto, não foi observada interação positiva entre a concentração proteica e energética da dieta oferecida, para os parâmetros, ou seja, independente da energia da ração, a exigência proteica aumentava, pois, foi influenciado pela percentagem de proteína bruta $(\mathrm{F}(2,16)=76, \mathrm{p}<0,0001)$ (Figura 2). Demonstrando que a concentração proteica das rações a ser fornecida para o jundiá, $R$. quelen deve ser de no mínimo de $30 \%$ de proteína bruta, proporcionando aos peixes incremento em biomassa, não diferindo $(\mathrm{P}>0,05)$ daqueles alimentados com $35 \%$ de proteína bruta.

Figura 2. Ganho em peso obtido nos jundiás, $R$. quelen, alimentados com diferentes percentagens de proteína bruta na ração. Letras distintas indicam diferenças significativas $(p<0,05)$ pelo teste modificado de Tukey (Zar, 1999).

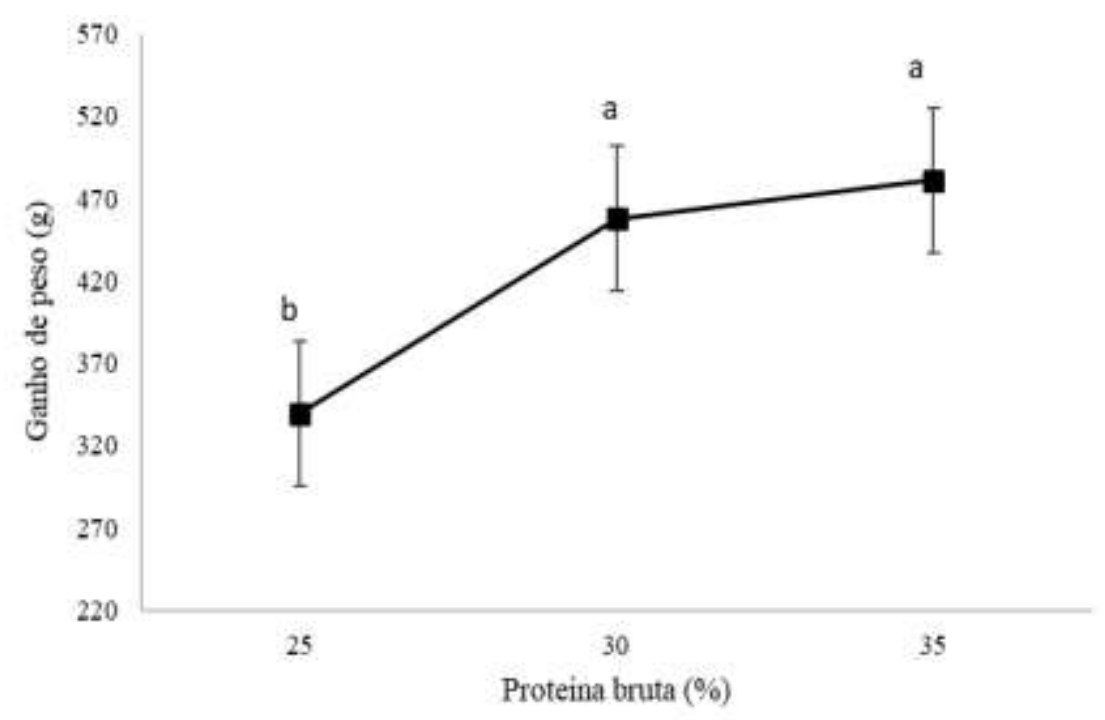

Fonte: Autores.

Os resultados observados para o jundia em tanques-rede, comprovam os observados por Meyer (2003) mostrou que o ganho em peso do $R$. quelen foi afetado pelo nível proteico da dieta, mas não pela concentração energética, quando testou cinco níveis de PB e dois de ED para alevinos de jundiá ( $R$. quelen). Contudo, o autor observou que existia interação significativa no ganho em peso entre a concentração energética de 3000 kcal, à medida que o nível proteico atingiu 38\%. Para o nível, proteico estes resultados se mostram semelhantes aos obtidos por Camargo et al. (2005) com juvenis de jundiá ( $R$. quelen) alimentados com dietas contendo 30, 40 e 50\% de proteína bruta e, não observaram diferenças significativas no desempenho dos animais. Freitas et al. (2011), avaliando proteína e energia para o jundia (R. voulezi) observaram a mesma resposta para o ganho de peso do $R$. voulezi.

As exigências proteicas para o jundia são elevadas, Piedras et al. (2006) observaram que para alevinos de jundiá (Rhamdia sp.), o melhor desempenho produtivo foi atingido com $51 \%$ PB e $3.400 \mathrm{kcal} / \mathrm{kg}$ ED, indicando que as necessidades de PB e ED para a espécie são elevadas, fator comprovado também por Uliana et al. (2001), Piedras et al. (2005), Vieira et al. (2006) e Tronco et al. (2007). Melo et al. (2006) notaram que juvenis de jundiá, Rhamdia quelen, alimentados com dietas contendo $41 \%$ de PB apresentaram valores mais elevados de ganho em peso e comprimento quando comparados aos níveis de 20, 27 e 34\% PB. A maioria das espécies de peixes nas fases iniciais necessita de maiores teores de PB em suas dietas quando comparadas às outras fases de desenvolvimento. 
Levando em consideração que os peixes consomem a dieta visando satisfazer suas necessidades energéticas, as rações com 25\% de proteína, apresentam uma relação de 13 e 14 kcal de ED/g PB. A relação energia:proteína que proporcionou o melhor resultado foi de 10,83 kcal ED/g PB, confirmando a recomendação de Meyer (2003) onde recomendam para o jundia R. quelen, de 7,71 a 10,32 kcal EM/g PB. Lopes et al. (2006), testando quatro níveis de energia (2.700, 3.000, 3.300 e 3.600 $\mathrm{kcal} / \mathrm{kg}$ ) e um de PB (35\%) na alimentação de alevinos de jundiá, constataram que o maior nível de energia apresentou melhora significativa com efeito linear sobre o crescimento, cuja relação energia:proteína é de 10,28. O conhecimento da relação energia: proteína é importante, pois Sá e Fracalossi (2002) afirmaram que alta relação de energia e proteína resultou na diminuição do consumo voluntário do alimento pelos peixes, mas por outro lado, baixa relação pode indicar o uso de proteína como fonte energética.

Em relação à fase de terminação (engorda), Piedras et al. (2004) citaram que são poucos os resultados obtidos até o momento. Por se tratar de espécie nativa e, de considerável valor econômico na região sul do país, a sua adaptação à temperatura da água é inerente da espécie. Sabe-se que a temperatura é fator importante para sua criação, pois influi no "bemestar”, crescimento, no aproveitamento do alimento e, consequentemente, na rentabilidade econômica da criação de jundiá.

Estes baixos resultados de GP podem ser atribuídos à variação de temperatura da água ao longo de todo o período estudado (Figura 3). Pode-se observar que quando os valores médios de temperatura da água atingiram seus menores índices houve leve acréscimo dos valores de GP médio diário. O inverso também ocorreu, entretanto, parece que os peixes puderam atingir um ponto ótimo de GP médio diário ao redor de $23^{\circ} \mathrm{C}$. Porém, observou-se que, nos meses de agosto e setembro, onde os valores médios de temperatura se mantiveram com médias de $20^{\circ} \mathrm{C}$, foi registrado os menores índices de GP médio diário (Figura 3). Analisando-se os dados observa-se que no mês de agosto, foram obtidos os menores valores da temperatura da água, que em alguns dias permaneceram abaixo de $18,0^{\circ} \mathrm{C}$. A temperatura é um fator determinante no desempenho produtivo destes animais, porém, inversamente proporcional, constatada por Signor (2006), onde mostrou a influência dos valores da temperatura da água sobre o ganho em peso do pacu Piaractus mesopotamicus, na qual quanto menor os valores de temperatura menores foram os de GP médio diário.

Figura 3. Representação gráfica do GP médio diário versus temperatura média mensal durante o período de cultivo do jundiá submetido ao arraçoamento com diferentes níveis de proteína bruta e energia digestível.

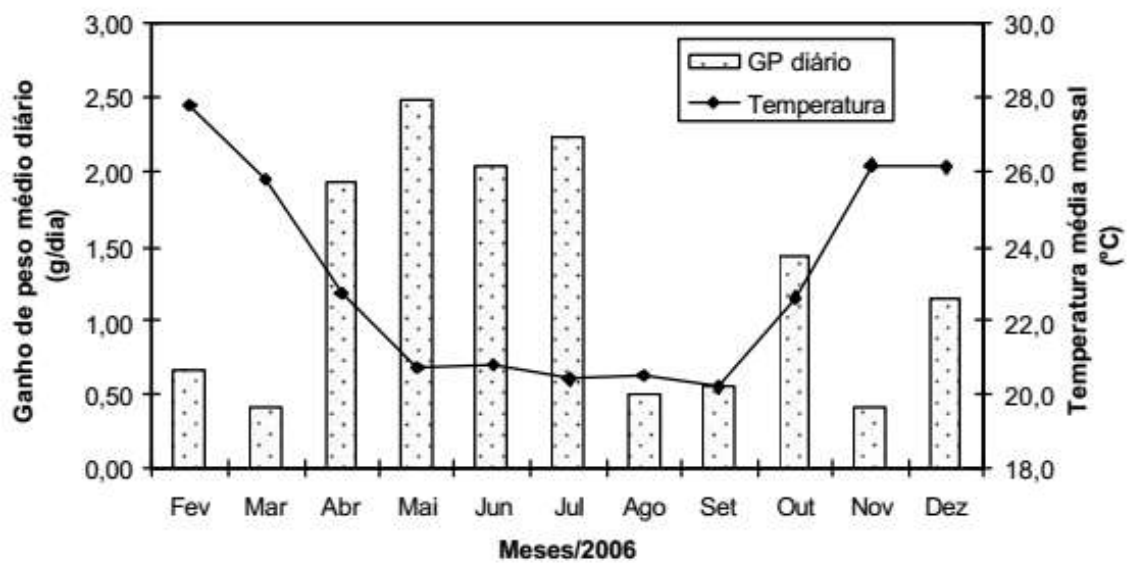

Fonte: Autores.

Observou-se que ocorreram grandes variações dos pesos, demonstrado pela grande amplitude do desvio-padrão. Isto sugere a necessidade de triagens periódicas e seleção por tamanho, para esta espécie, quando em confinamento, pois, a variação do peso médio final, apresentou desvio-padrão muito amplo, o que sugere influência deste sistema na heterogeneidade 
do lote. Segundo Ozorio et al. (2004) e Campos (2005) o segredo de terminação bem-sucedida dos bagres está no sistema e eficiência de triagem durante o crescimento, pois quanto mais homogêneos os lotes de peixes, maior a produção final. Entretanto, Liranço et al. (2011) estudando bagres de grande porte (Pseudoplatystoma corruscans) asseguraram que, em pesquisa torna-se impossível selecioná-los por tamanho devido ao número de indivíduos e ao número de repetições que devem ser mantidas ("n" da amostra). Estas observações sobre a desuniformidade visual também foram descritas por Baldisserotto e Radünz Neto (2005), em revisão realizada para o gênero Rhamdia, onde citaram que a discrepância do tamanho das fêmeas em relação aos machos (20-32\%).

Neste estudo, a taxa de sobrevivência, durante os 12 meses, variou de 60 a 80\%, não mostrando diferenças significativas entre os fatores analisados (PB e ED). Estes valores foram similares aos encontrados por Santo e Amaral-Júnior (2003) que obtiveram taxas médias de sobrevivência de $57 \%$ quando os jundiás foram mantidos em viveiros escavados em terra, durante 240 dias. Entretanto, neste caso, os peixes estocados inicialmente, apresentavam pesos variando de $2 \mathrm{a} 4 \mathrm{~g}$.

Conforme o esperado, os valores da CAA melhoraram com a taxa de sobrevivência. Assim, os efeitos dos fatores (PB e ED) foram avaliados sobre a sobrevivência média de cada TR individual, ou seja, as CAA foram ajustadas para os valores médios de sobrevivência de 79,35\%. Semelhante, ao ganho em peso, a quantidade de ED parece não ter afetado a CAA, enquanto que, a porcentagem de PB na ração teve efeito significativo $\left(F_{(2,15)}=13,22, p=0,0004\right.$; Figura 4), sendo que, o nível de $25 \%$ apresentou os piores resultados quando comparados aos de 30 e 35\%, os quais não diferiram $(\mathrm{P}>0,05)$ entre si.

Figura 4. Conversão alimentar aparente (ajustada à sobrevivência de 79,35\%) obtida nas unidades experimentais submetidas a diferentes percentagens de proteína bruta na ração. Letras distintas indicam diferenças significativas $(p<0,05)$ pelo teste modificado de Tukey (Zar, 1999).

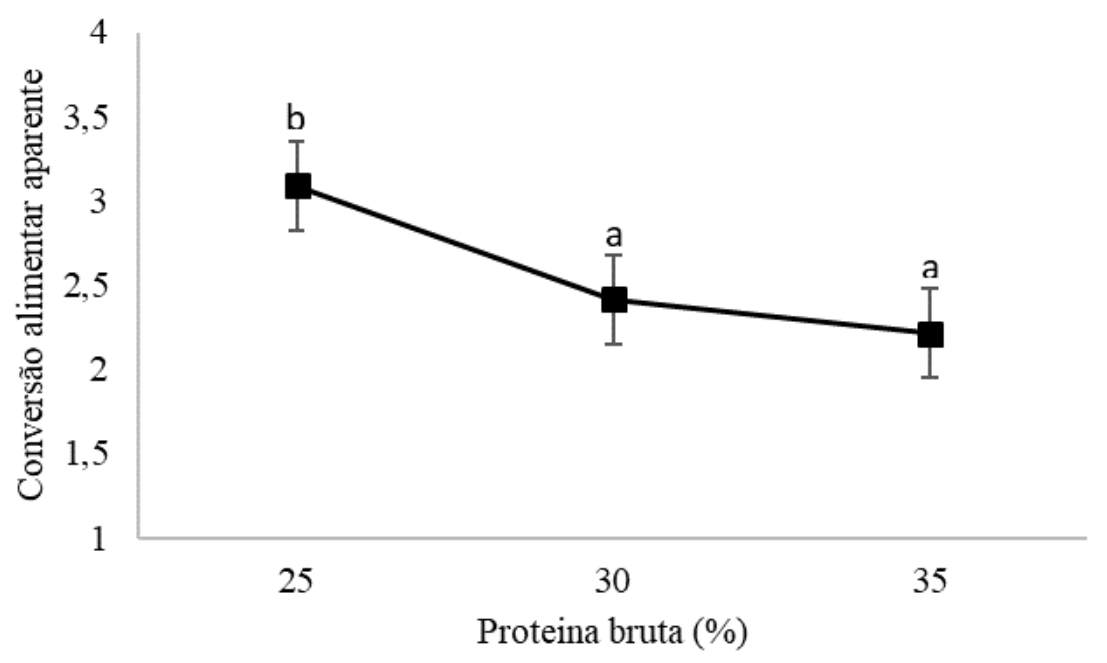

Fonte: Autores.

Avaliando a CAA, Freitas et al. (2011) observaram interação dos fatores comprovou que, com o aumento da concentração proteica e energética da dieta, a conversão alimentar diminuiu e os melhores resultados foram observados nos peixes alimentados com as dietas contendo 30 e $35 \%$ de proteína bruta e $3.500 \mathrm{kcal}$ de energia digestível kg $\mathrm{kg}^{-1}$. No trabalho com $R$. quelen, os valores de CAA obtidos foram melhores que os encontrados por Souza (2002), que cultivou jundiás (peso de $80 \mathrm{~g}$ ), em viveiros escavados em terra, durante 135 dias, com temperaturas de 11,0 a $29,0^{\circ} \mathrm{C}$ e obtiveram médias de CAA de 3:1. Entretanto, Piedras et al. (2004) mostraram valores médios de CAA iguais a 1,6:1, melhores aos encontrados no presente trabalho. Este melhor índice de CAA pode ser explicado, pois, o experimento foi conduzido em condições laboratoriais, com indivíduos jovens e por menor período. 
Os valores de CAA desta pesquisa estão mais próximos dos encontrados por Signor et al. (2010) com o pacu, Piaractus mesopotamicus, também em tanques-rede, alimentados com a mesma dieta experimental, onde os valores de CAA foram de 2,82:1. No reservatório da Usina Hidrelétrica de Itaipu, município de Santa Helena, durante a realização deste experimento, os peixes se apresentaram, constantemente agitados. Os jundiás mantidos em TR não tinham onde se refugiar, o que provavelmente os levou a estresse permanente, influenciando no desempenho produtivo desses animais. Uma das prováveis causas refere-se aos valores médios de transparência da água que nunca atingiram valores médios inferiores a 2,0 m, outro fator que, pode ter auxiliado neste baixo desempenho possa ter sido a ampla variação dos valores de temperatura durante o período experimental.

No sentido de aprimorar a produção de jundiás recomenda-se mais pesquisas que simulem adequadas densidades de estocagem, de tanques-redes mais profundos (evitando a influência da luz solar) e dietas mais eficazes, entre outros. Por se tratar de espécie nativa e, de considerável valor econômico na região sul do país, seu estudo continua sendo desafio, a espera de novas metas.

\section{Conclusão}

O jundiá, R. quelen, apresenta melhor desempenho produtivo com ração contendo $30 \%$ de $\mathrm{PB}$, independentemente das concentrações de ED (3.250 ou $3.500 \mathrm{kcal} / \mathrm{kg}$ ), contudo, recomenda-se o uso de $3.250 \mathrm{kcal}$ de ED/kg levando-se em consideração as condições de cultivo empregadas.

Novos estudos devem ser conduzidos visando a consolidação das informações, inclusive com informações adicionais como histologias e hematologias, visando observar o estado nutricional dos animais.

\section{Referências}

Baldisserotto, B., \& Radünz Neto, J. (2005). Jundiá (Rhamdia sp.). In: Baldisserotto, B., \& Gomes, C. L. Espécies nativas para piscicultura no Brasil. Santa Maria, Editora UFSM, p.303-319.

Boscolo, W. R., Hayashi, C., \& Meurer, F. (2002). Digestibilidade aparente da energia e nutrientes de alimentos convencionais e alternativos para a tilápia do Nilo (Oreochromis niloticus, L.). Revista Brasileira de Zootecnia, Viçosa, 13 (2), 539-545.

Boyd, C. (1990). Water quality in ponds for aquaculture: Birmingham Publishing, 482p.

Camargo, S. O., Pouey, J. L., \& Martins, C. (2005). Parâmetros eritrocitários do jundiá (Rhamdia quelen) submetido à dieta com diferentes níveis de proteína. Ciência Rural, 35 (6), 1406-1411.

Campos, J. L. (2005). O cultivo do pintado, Pseudoplatytoma coruscans (Spix e Agassiz, 1829). In: Baldisserotto, B., \& Gomes, L. DE C. Espécies nativas para a piscicultura no Brasil. Santa Maria, Editora UFSM, 327-344.

Carneiro, P. C. F. A (2004). Produção do jundiá em cativeiro. In: Baldisserotto, B., \& Radünz Neto, J. Criação de Jundiá. Santa Maria, Editora UFSM, p.117141.

Carneiro, P. C. F., Bendhack, F., Mikos, J. D., Schorer, M., \& Oliveira Filho, P. R. C. (2002). Resultados preliminares sobre o jundiá, Rhamdia quelen, como espécie importante para a piscicultura na região Sul do Brasil. Anais... In: Simpósio brasileiro de aqüicultura, 12, 2002 , goiânia: caunesp/esalq, 403, p.11.

Carneiro, P. C. F., \& Mikos, J. D. (2005). Freqüência alimentar e crescimento de alevinos de jundiá, Rhamdia quelen. Ciência Rural, 35 (1), $187-191$.

Coldebella, I. J., \& Radünz Neto, J. (2002). Farelo de soja na alimentação de alevinos de jundiá (Rhamdia quelen). Ciência Rural, 32 (3), $499-503$.

Duan, Q., Mai, K., Zhong, H., Si, L., \& Wang, X. (2001). Studies on the nutrition of the large yellow croaker, Pseudosciaena crocea R. I: growth response to graded levels of dietary protein and lipid. Aquaculture Research, 32, 46-52.

Ellis, S. C., \& Reigh, R. C. (1991). Effects of dietary lipid and carbohydrate levels on growth and body composition of juvenile red drum (Sciaenops ocellatus). Aquaculture, 97, 383-394.

Felin Junior, R., Coldebella, J. I., \& Manfio, M. L. (2007). Avaliação de machos e fêmeas de Rhamdia quelen criados em tanques-rede de pequeno volume. In: Workshop sobre jundiá. Anais... Santa Maria, RS, p.41.

Fracalossi, D. M., Zaniboni Filho, E., \& Meurer, S. (2002). No rastro das espécies nativas. Panorama da Aqüicultura, 12 , 43-49. 
Freitas, J. M. A., Sary, S., Luchesi, J. L., Feiden, A., \& Boscolo, W. R. (2011). Proteína e energia na dieta de jundiás criados em tanques-rede. Revista Brasileira de Zootecnia, 40 (12), 2628-2633.

Furuya, W. M., Hayashi, C., \& Furuya, V. R. B. (1996). Exigência de proteína para machos revertidos de tilápia do Nilo (Oreochromis niloticus L.) na fase juvenil. Revista Unimar, 18 (2), 307-319.

Gotelli, N. J., \& Ellison, A. M. (2004). A primer of ecological statistics: Sinauer press.

Huitema, B. E. (1980). The analysis of covariance and alternatives: Wiley- Interscience.

Lazzari, R., Radünz Neto, J., Emanuelli, T., Pedron, F. A., Costa, M. L., Losekann, M. E., Correia, V., \& Bochi, V. C. (2006). Diferentes fontes protéicas para a alimentação do jundiá (Rhamdia quelen). Ciência Rural, 36 (1), 240-246.

Liranço, A. D. S., Romagosa, E., \& Scorvo Filho, J. D. (2011). Efeito dos sistemas de criação semi-intensivo (viveiro escavado) e intensivo (tanque-rede) no desenvolvimento produtivo do pintado, Pseudoplatystoma corruscans (SPIX \& AGASSIZ, 1829) (Siluriformes: Pimelodidae). Ciência Rural, 41 (3), 524-530.

Lopes, P. R. S., Pouey, J. L. O. F., Enke, D. B. S., Martins, C. R., \& Timm, G. (2006). Desempenho de alevinos de jundiá Rhamdia quelen alimentados com diferentes níveis de energia na dieta. Revista Biodiversidade Pampeana. 4, 32-37.

Lovell, R. T. (1998). Nutrition and Feeding of fish. (2a ed.): Kluwer Academic Publishers, 267 p.

Lovell, R. T. (1991). Nutrition of Aquaculture species. Journal of Animal Science, 69, 4193-4200.

Melo, J. F. B., Lundstedt, L. M., Metón, I., Baanante, I. V., \& Moraes, G. (2006). Effects of dietary levels of protein on nitrogenous metabolism of Rhamdia quelen (Teleostei: Pimelodidae). Comparative Biochemistry and Physiology, 145, 181-187.

Meyer, G. (2003). Exigência protéica em duas concentrações energéticas da dieta e estimativa da exigência em aminoácidos essenciais para alevinos de jundiá, Rhamdia quelen. Dissertação de Mestrado, Pós-graduação em Aqüicultura, Santa Catarina, 50p. 2003.

Ng, W. K., Soon, S. C., \& Hashim, R. (2001). The dietary requirement of bagrid catfish, Mystus nemurus (Cuvier \& Valenciennes), determined using semupurified diets of varying protein levels. Aquaculture Nutrition, 7 (1), 45-51.

Ozorio, R. O. De A., Avnimelech, Y., \& Castagnolli, N. In: Cyrino, J. E. P., Urbinati, E. C., Fracalossi, D. M., \& Castagnolli, N. (2004). Tópicos especiais em piscicultura de água doce intensiva. São Paulo: Tec.Art., p.7-24.

Pezzato, L. E., Miranda, E. C., Barros, M. M., Pinto, L. G. Q., Furuya, W. M., \& Pezzato, A. C. (2002). Digestibilidade aparente de ingredientes pela tilápia do Nilo Oreochromis niloticus. Revista Brasileira de Zootecnia, 31 (4), 1595-1604.

Piedras, S. R. N., Morae, P. R. R., Isoldi, L. A., Pouey, J. L. O. F., \& Rutz, F. (2005). Comparação entre o selênio orgânico e o inorgânico empregados na dieta de alevinos de jundiá (Rhamdia quelen). Boletim do Instituto de Pesca, 31 (2), 171-174.

Piedras, S. R. N., Moraes, P. R. R., \& Pouey, J. L. O. F. (2006). Resposta de alevinos de jundiá (Rhamdia sp.) alimentados com diferentes níveis de proteína bruta e energia digestível. Revista Brasileira Agrociência, 12 (2), 217-220.

Piedras, S. R. N., Moraes, P. R. R., \& Pouey, J. L. O. F. (2004). Crescimento de juvenis de jundiá (Rhamdia quelen), de acordo com a temperatura da água. Boletim do Instituto de Pesca, 30 (2), 177-182.

Pereira, A. S., Shitsuka, D. M., Parreira, F. J., \& Shitsuka, R. (2018). Metodologia da pesquisa científica. UFSM.

Rostagno, H. S., Albino, L. F. T., Donzele, J. L., Gomes, P. C., Oliveira, R. F., Lopes, D. C., Ferreira, A. S., \& Barreto, S. L. T. (2005). Tabelas Brasileiras para aves e Suínos - Composição dos alimentos e exigências nutricionais. Viçosa, (2a ed.), 141p.

Sá, M. V. C., \& Fracalossi, D. M. (2002). Exigência protéica e relação energia:proteína para alevinos de piracanjuba (Brycon orbignyanus). Revista Brasileira de Zootecnia, 1 (31), 1-10.

Santo, G., \& Amaral Júnior, H. (2003). Comparative growth test between gray and pink jundiá Rhamdia sp. and nile tilapia Oreochromis niloticus. In: World Aquaculture, 2003, Salvador. Book of Abstracts... Salvador: WAS. 2. 700p.

Shiau, S. Y., \& Lan, C. W. (1996). Optimum dietary protein level and protein to energy ratio for growth of grouper (Epinephelus malabaricus). Aquaculture, 145 (4), 259-266.

Signor, A. A. (2006). Níveis de proteína e energia na alimentação do pacu (Piaractus mesopotamicus Holmberg 1887) cultivados em tanques-rede no reservatório de Itaipu. Trabalho de conclusão de curso. Curso Engenharia de Pesca - UNIOESTE/Campus de Toledo, 56p.

Signor, A. A., Boscolo, W. R., Feiden, A., Bittencourt, A., Coldebella, A., \& Reidel, A. (2010). Proteína e energia na alimentação de pacus criados em tanques-rede. Revista Brasileira de Zootecnia, 39 (11), 2336-2341.

Signor, A. A., Reidel, A., Coldebella, A., Ferreira, H. K. A., Signor, F. R. P., \& Watanabe, A. L. (2020). Densidade de estocagem de jundiá (Rhamdia quelen) em tanques-rede na fase inicial. Brazilian Journal of Development, 6 (7), 43975-43985.

Souza, L. S. (2002). Avaliação do desempenho de jundiá (Rhamdia sp.) e catfish (Ictalurus punctatus) em tanque de terra. Dissertação de Mestrado, Universidade Federal de Pelotas, 108p.

STATSOFT (2005). STATISTICA (data analysis software system), version 7.1. www.statsoft.com.

Tronco, A. P., Radünz Neto, J., Medeiros, T. S., \& Lima, R. L. (2007). Alimentação de larvas de jundiá (Rhamdia quelen) com dietas semipurificadas e fontes lipídicas. Boletim do Instituto de Pesca, 33 (1), 9-17. 
Research, Society and Development, v. 10, n. 2, e56210212638, 2021

(CC BY 4.0) | ISSN 2525-3409 | DOI: http://dx.doi.org/10.33448/rsd-v10i2.12638

Uliana, O., Silva, J. H. S., \& Radünz Neto, J. (2001). Diferentes fontes de lipídios testadas na criação de larvas de jundiá (Rhamdia quelen), Pisces Pimelodidae. Ciência Rural, 31 (1), 129-133.

Vieira, V. L. P., Radünz Neto, J., Lopes, P. R. S., Lazzari, R., Fonseca, M. B., \& Menezes, C. C. (2006). Alterações metabólicas e hematológicas em jundiás (Rhamdia quelen) alimentados com rações contendo aflatoxinas. Ciência Ambiental Brasileira, 7 (1), 49-55.

Zar, J. H. (1999). Biostatistical analysis. (4a ed.) Prentice Hall, 663p. 